\title{
APLIKASI MOBILE PENCARIAN JALUR ANGKUTAN UMUM DI KOTA CIMAHI BERBASIS ANDROID
}

\author{
Lela Kesmasari $^{1)}$, Castaka Agus Sugianto ${ }^{2)}$ \\ 1,2) Program Studi Teknik Informatika Politeknik TEDC Bandung \\ E-mail: Lela.kesmasari@gmail.com ${ }^{1)}$, castaka@poltektedc.ac.id ${ }^{2)}$
}

\begin{abstract}
Abstrak
Kelebihan-kelebihan yang dimiliki handphoneandroid menyebabkan banyak masyarakat beralih menggunakan handphoneandroid. Permasalahan yang timbul adalah perkembangan teknologi yang semakin meningkat dengan segala kebutuhan tertentu maka harus diimbangi juga dengan dukungan aplikasi yang mampu memenuhi kebutuhan manusia, sehingga lebih mudah dan lebih efisien. Kota Cimahi merupakan daerah penyangga bagi kota Bandung yang berjarak $12 \mathrm{~km}$ di sebelah barat. Adapun turis yang mengunjungi kota Cimahi serta mahasiswa yang merantau untuk melanjutkan pendidikannya di Cimahi. Sebagian besar mahasiswa bepergian menggunakan angkutan umum. Kota Cimahi juga merupakan markas dari 31 kesatuan tentara dan polisi. Sebagian besar para tentara tidak diperkenankan membawa kendaraan bermotor, maka mereka harus menggunakan angkutan umum yang berada di kota Cimahi. Serta dikarenakan banyaknya masyarakat kota Cimahi yang tidak mengetahui jalur angkutan umum, dan sering kalinya penumpang keliru menaiki angkutan umum yang menyebabkan penumpang tersesat. Atas dasar inilah maka penulis ingin membuat suatu aplikasi android tentang angkutan umum dengan harapan agar dapat membantu setiap penduduk kota Cimahi yang menyukai berkendara dengan angkuatan umum agar dapat mengetahui angkutan mana yang harus ditumpangi untuk sampai ke tujuan. Pembuatan aplikasi android ini dirancang menggunakan software Eclipse Java Indigo (Open Source).Dan untuk mempermudah dalam tahap perancangan digunakan Use Case Diagram dan Diagram Activity.
\end{abstract}

Kata kunci : tarik Android, Angkutan Umum, Eclipse Java Indigo

\section{Pendahuluan}

Keberadaan sebuah handphone tidak bisa dipandang sebelah mata. Pada zaman ini, handphone telah menjadi semacam kebutuhan pokok dari masyarakat. Perkembangan teknologi dan kesiapan dari penyedia layanan seluler telah mengubah fungsi handphone yang sebelumnya hanya sebagai alat komunikasi sekarang telah menjadi alat komputasi yang memiliki sistem operasi layaknya sebuah komputer. Android merupakan salah satu sistem operasi yang dewasa ini tengah berkembang di masyarakat. Terdapat keunggulan dari sistem operasi ini antara lain sistem operasinya dapat diubah sesuai dengan keinginan kita sendiri. Seining berkembangnya produk handphone, para produsen penyedia provider juga menyediakan layanan internet untuk memudahkan setiap penggunanya mendapatkan informasi yang diinginkan dimana saja dan kapan saja, yaitu dengan menanamkan aplikasi pencarian pada smartphone Android (Arif Humala, 2012). Sedangkan Java merupakan salah satu bahasa pemrograman yang bisa digunakan untuk mengembangkan suatu aplikasi yang bisa digunakan pada handphone berbasis android (Yuniar Supardi, 2010). Keberadaan sistem operasi ini akan bertanggung jawab dalam mengoperasikan berbagai fungsi dan fitur yang tersedia dalam perangkat ponsel, dari segi entertainment dan fungsionalitas penggunaan selular untuk memudahkan tugas seharihari seperti memudahkan pengguna dalam mengatur 
file dan menginstall aplikasi sehingga memberikan fungsi lebih pada perangkat handphone tersebut. Dengan adanya kelebihan yang dimiliki handphone android maka banyak masyarakat beralih menggunakan jenis handphone tersebut.

Android telah banyak berkembang dari mulai android versi 1.1 sampai yang terbaru android versi 4.0 atau dipanggil dengan sebutan Ice Cream Sandwich. Setiap perkembangan dari versi ke versi android selalu menambahkan kelebihan, kelebihan ini dapat dilihat dari semakin besar versi yang dimiliki semakin cepat kinerja dari handphone tersebut dan juga semakin banyak aplikasi yang support. Dengan adanya sistem operasi Android ini membuat para Application Development (pembuat aplikasi) mulai beralih membuat aplikasi untuk android yang biasa disebut Android Application Development. Tugas dari para Android Application Development adalah untuk memenuhi kebutuhan pengguna handphone android. Pembuatan aplikasi android dapat lebih mempermudah perkerjaan, dimana sebelumnya perkerjaan tersebut hanya dapat dilakukan melalui komputer kini bisa dilakukan hanya dengan smartphone android (Nazaruddin Safaat H, 2012). Melihat perkembangan teknologi peranti mobile yang didukung oleh mikroprosesor kecepatan tinggi dan internet, menciptakan akses di setiap waktu dan tempat membuat segala sesuatunya menjadi lebih efektif. Permasalahan yang timbul adalah perkembangan teknologi yang semakin meningkat dengan segala kebutuhan tertentu maka harus diimbangi juga dengan dukungan aplikasi yang mampu memenuhi kebutuhan manusia, sehingga lebih mudah dan lebih efisien.

Kota Cimahi merupakan daerah penyangga bagi kota Bandung yang berjarak $12 \mathrm{~km}$ di sebelah barat. Adapun turis yang mengunjungi kota Cimahi serta mahasiswa yang merantau untuk melanjutkan pendidikanya di Cimahi. Sebagian besar mahasiswa bepergian menggunakan angkutan umum. Kota Cimahi juga merupakan markas dari 31 kesatuan tentara dan polisi. Pusat pendidikan militer bisa dijumpai di kota ini, mulai dari brigade infanteri, artileri medan, sampai pasukan kavaleri (Data Kota Cimahi Tahun 2009). Banyak tentara pun berasal dari berbagai daerah di Indonesia. Sebagian besar para tentara tidak diperkenankan membawa kendaraan bermotor, maka mereka harus menggunakan angkutan umum yang berada di kota Cimahi, Serta dikarenakan banyaknya masyarakat kota Cimahi yang tidak mengetahui jalur angkutan umum, dan sering kalinya penumpang keliru menaiki angkutan umum yang menyebabkan penumpang tersesat. Atas dasar inilah maka penulis mencoba memberikan solusi dengan membangun sebuah "APLIKASI MOBILE PENCARIAN J ALUR ANGKUTAN UMUM DI KOTA CIMAHI BERBASIS ANDROID", dengan harapan agar dapat membantu setiap penduduk kota Cimahi yang menyukai berkendara dengan angkuatan umum agar dapat mengetahui angkutan mana yang harus ditumpangi untuk sampai ke tujuan.

\section{Landasan Teori \\ 2.1 Aplikasi Mobile}

Aplikasi bergerak merupakan istilah yang digunakan untuk suatu aplikasi yang dijalankan pada perangkat mobile yang cenderung memiliki ukuran kecil, portable dan dapat terkoneksi melalui jaringan nirkabel. Perangkat mobile memiliki banyak jenis dalam hal ukuran, desain dan layout, tetapi mereka memiliki kesamaan karakteristik yang sangat berbeda dari sistem desktop. (Evalin Marta Damayanti Sihombing, Guntur Prabawa Kusuma, dan Hendra Kusmayadi, 2013)

\subsection{Angkutan Umum}

Angkutan pada dasarnya adalah sarana untuk memindahkan orang atau barang dari satu tempat ke tempat lain. Tujuannya membantu orang atau kelompok orang yang menjangkau berbagai tempat yang dikehendaki atau mengirimkan barang dari tempat asalnya ke tempat tujuannya. Prosesnya dapat dilakukan dengan menggunakan sarana angkutan berupa kendaraan. Sementara Angkutan Umum Penumpang adalah angkutan penumpang yang menggunakan kendaraan umum yang dilakukan dengan sistem sewa atau bayar. Termasuk dalam pengertian angkutan umum penumpang adalah angkutan kota (bus, minibus, dsb), kereta api, angkutan air, dan angkutan udara.

Angkutan umum biasanya diklasifikasan atas 3 karakteristik yang berbeda, yaitu: (Universitas Sumatera Utara)

1. Karakteristik J alan (Right of Way atau R/W)

2. Karakteristik Teknologi

3. Karakteristik Tipe Pelayanannya

Untuk klasifikasi angkutan umum berdasarkan karakteristik jalan (right of way), jenis angkutan umum dapat dibedakan menjadi 3 kategori, yaitu :

a. Kategori A : "Grade Separated" atau jalur khusus Umumnya memiliki akses keluar dan masuk yang khusus dan hanya dapat dimasuki oleh jenis kendaraan tertentu.

b. Kategori B

Umumnya merupakan jalan biasa, di mana terjadi persinggungan antara 2 jenis moda atau lebih. 
Sebagai contoh jalan persimpangan di mana terdapat dua rel kereta api.

c. Kategori C

Merupakan jalan dengan sistem lalu lintas campuran, umumnya sistem jaringan bus dan jaringan kendaraan umum lainnya yang masuk ke dalam kategori ini.

Kategori tipe Pelayanan mengklasifikasikan angkutan umum menjadi tiga kelompok yaitu :

1. Short Haul

Pelayanan untuk kecepatan minimum. Umumnya terdapat di daerah yang kecil dan jumlah populasi penduduk tidak terlalu besar, kecepatan kendaraan yang diizinkan juga kecil.

2. City Transit

Merupakan tipe yang paling banyak ditemui, di mana tipe ini melayani kebutuhan transportasi masyarakat di daerah perkotaan.

3. Regional Transit / Long Haul

Umumnya untuk kendaraan dengan desain kecepatan tinggi, contohnya jaringan kereta api atau sistem bus cepat.

\subsection{Jalur Angkutan Umum}

Jalur angkutan umum adalah infrastruktur dan pelayanan yang disediakan pada jalan yang telah ditentukan untuk jalur bus atau kereta pada jadwal yang telah ditetapkan (Junior Alberto, 2008).

\subsection{Android}

Android adalah sistem operasi yang berbasis Linux untuk telepon seluler seperti telepon pintar dan komputer tablet. Android menyediakan platform terbuka bagi para pengembang untuk menciptakan aplikasi mereka sendiri untuk digunakan oleh bermacam peranti bergerak. Awalnya, Google Inc. membeli Androidlnc., pendatang baru yang membuat peranti lunak untuk ponsel. Kemudian untuk mengembangkan Android, dibentuklah Open Handset Alliance, konsorsium dari 34 perusahaan peranti keras, peranti lunak, dan telekomunikasi, termasuk Google, HTC, Intel, Motorola, Qualcomm, TMobile, dan Nvidia (Arif Humala, Pembuatan Aplikasi Pencarian Halte Transjakarta Terdekat Berbasis Android).

Untuk mengembangkan Android agar bisa lebih baik lagi, oleh Google yang sebelumnya membeli Android Inc dibentuklah Open Handset Alliance yang kemudian Open Handset Alliance mendukung dikembangkannya lagi standar terbuka di perangkat seluler. Tidak hanya itu saja, Google juga merilis kode-kode Android di bawah lisensi Apache, sebuah lisensi perangkat lunak dan standar terbuka perangkat seluler (Rizki Pratiwi, Ary Mazharudin Shiddiqi, dan Baskoro Adi Pratomo, 2012).

\subsection{UML (Unified Modelling Language)}

UML (Unified Modeling Language) adalah sebuah bahasa untuk menetukan, visualisasi, kontruksi, dan mendokumentasikan artifact (bagian dari informasi yang digunakan atau dihasilkan dalam suatu proses pembuatan perangkat lunak. Artifact dapat berupa model, deskripsi atau perangkat lunak) dari system perangkat lunak, seperti pada pemodelan bisnis dan sistem non perangkat lunak lainnya (Riza Prasetya Yosandha, Suyatinongsih, dan Toufan D Tambunan, 2012).

\subsection{Eclipse}

Eclipse adalah sebuah IDE (Integrated Development Environment) untuk mengembangkan perangkat lunak dan dapat dijalankan di semua platform (platform-independent). Berikut adalah sifat Eclipse: (Arif Humala, Pembuatan Aplikasi Pencarian Halte Transjakarta Terdekat Berbasis Android)

1. Multi-platform

Target sistem operasi Eclipse adalah Microsoft Windows, LinuX, Solaris, AIX, HP-UX dan Mac OS X.

2. Mulit-language

Eclipse dikembangkan dengan bahasa pemrograman Java, akan tetapi Eclipse mendukung pengembangan aplikasi berbasis bahasa pemrograman lainnya, seperti $\mathrm{C} / \mathrm{C}++$, Cobol, Python, Perl, PHP, dan lain sebagainya.

3. Multi-role

Selain sebagai IDE untuk pengembangan aplikasi, Eclipse pun bisa digunakan untuk aktivitas dalam siklus pengembangan perangkat lunak, seperti dokumentasi, test perangkat lunak, pengembangan web, dan lain sebagainya.

Eclipse pada saat ini merupakan salah satu IDE favorit dikarenakan gratis dan open source, yang berarti setiap orang boleh melihat kode pemrograman perangkat lunak ini. Selain itu, kelebihan dari Eclipse yang membuatnya populer adalah kemampuannya untuk dapat dikembangkan oleh pengguna dengan komponen yang dinamakan plug-in. Secara standar Eclipse selalu dilengkapi dengan JDT (J ava Development Tools), plug-in yang membuat Eclipse kompatibel untuk mengembangkan program Java, dan PDE (Plug-in Development Environment) untuk mengembangkan plug-in baru. Eclipse beserta plugin-nya diimplementasikan dalam bahasa pemrogramanl ava.

Konsep Eclipse adalah IDE adalah

1. terbuka (open),

2. mudah diperluas (extensible) untuk apa saja, 
3. tidak untuk sesuatu yang spesifik.

Eclipse tidak saja untuk mengembangkan program Java, tetapi juga untuk berbagai macam keperluan. Perluasan apapun cukup dengan menginstal plug-in yang dibutuhkan. Apabila ingin mengembangkan program $\mathrm{C} / \mathrm{C}++$ maka telah terdapat plug-in CDT(C/C++ Development Tools) yang dapat dipasang di Eclipse untuk Eclipse menjadi perangkat untuk pengembangan $\mathrm{C} / \mathrm{C}++$. (Wina Noviani Fatimah, 2011)

\subsection{Java}

Java merupakan bahasa pemrograman yang dikembangkan dari bahasa pemrograman C++, sehingga bahasa pemrograman ini seperti bahasa $\mathrm{C}++$.Perangkat lunak Java memiliki edisi yang lengkap untuk beberapa masalah, yaitu pemrograman desktop atau aplikasi, pemrograman database atau enterprise, dan pemrograman mobile (handphone).J ava diciptakan oleh James Gosling dan Patrick Naughton dalam suatu project, dengan kode hijau (Green Code) di Sun Microsystem. Pada mulanya ingin diberi nama OAK dari pohon yang terdapat pada kantor James Gosling, tetapi OAK telah ada pada Sun Microsystem, maka diberi nama Java (inspirasi dari nama kopi). Browser pertama yang dapat membaca J ava adalah Hot Java (Yuniardi Supardi, 2010).

\subsection{Profil Kota Cimahi}

Kota Cimahi merupakan sebuah Kota di Provinsi J awa Barat, Indonesia. Kota ini terletak di sebelah barat Kota Bandung.Cimahi mulai dikenal pada tahun 1811, ketika Gubernur Jendral Herman Willem Daendels membuat jalan Anyer-Panarukan, dengan dibuatnya pos penjagaan di alun-alun Cimahi sekarang. Tahun 1847-1983, dilaksanakan pembuatan jalan kereta api Bandung-Cianjur sekaligus pembuatan stasiun kereta cimahi. Tahun 1886 dibangun pusat pendidikan militer beserta fasilitas lainnya seperti Rumah Sakit Dustira dan rumah tahanan militer.Pada tahun 1935, Cimahi ditetapkan sebagai kecamatan.

Setelah kemerdekaan Indonesia, Cimahi menjadi bagian dari Kabupaten Bandung Utara.Pada tahun 1962, dibentuk kawedanan Cimahi yang meliputi Kecamatan Cimahi, Padalarang, Batujajar, dan Cipatat. Berdasarkan PP Nomor 29 Tahun 1975, Cimahi ditingkatkan statusnya menjadi kota administratif pada tanggal 29 Januari 1976, dan menjadi kota administratif pertama di Jawa Barat. Mulai tanggal 21 Juni 2001 status Cimahi menjadi Kota Otonom, yang terdiri atas tiga kecamatan, dengan 15 kelurahan (Sekilas Sejarah Kota Cimahi). Kota Cimahi juga dikenal sebagai "Kota Tentara" karena di Kota ini banyak didirikan pusat pendidikan untuk tentara. Hampir terdapat sekitar 24 bangunan militer yang juga merupakan Bangunan Cagar Budaya yang harus dilestarikan di Kota Cimahi, diantaranya: (Profil Kota Cimahi)

1. Pusat Pendidikan Artileri (Pusdik Art)

2. Pusat Pendidikan Artileri Medan (Pusdik Armed)

3. Pusat Pendidikan Guru Militer (Pusdik Gumi)

4. Pusat Pendidikan Infanteri (Pusdik In)

5. Pusat Pendidikan Jasmani (Pusdik Jas)

6. Pusat Pendidikan Pal (Pusdik Pal)

7. Pusat Pendidikan Perbekalan dan Angkutan (Pusdik Bekang)

8. Pusdik Pendidikan Polisi Militer (Pusdik Pom) Dengan banyaknya pusat pendidikan tentara dan fasilitas kemiliteran lainnya maka sekitar $60 \%$ wilayah Kota Cimahi digunakan oleh tentara, mungkin karena itulah, Kota Cimahi juga mendapatkan julukan "Kota Hijau", sesuai dengan warna seragam yang digunakan tentara khususnya dari angkatan darat (TNI-AD).

\subsection{Dinas Perhubungan (Dishub) Kota Cimahi} Dinas Perhubungan kota Cimahi merupakan unsur pelaksana otonomi daerah Cimahi, yang menyelenggarakan sebagian urusan Pemerintahan Daerah di bidang perhubungan. Dinas Perhubungan dipimpin oleh Kepala Dinas. Kepala Dinas berkedudukan di bawah dan betanggung jawab kepada Walikota melalui Sekertaris Daerah. Pada Dinas Perhubungan dapat dibentuk unit pelaksana teknis dinas untuk melaksanakan sebagian kegiatan teknis operasional dan/atau kegiatan teknis penunjang yang mempunyai wilayah kerja (Dinas Perhubungan, 2010).

Tugas Pokok dan Fungsi Dinas Perhubungan

1. Dinas Perhubungan mempunyai tugas pokok melaksanakan sebagian urusan Pemerintahan Daerah, dibidang Perhubungan, Komunikasi dan Informatika.

2. Dinas Perhubungan dalam tugas pokok menyelenggarakan fungsi:

a. Perumusan kebijakan teknis bidang Perhubungan, Komunikasi dan Informatika.

b. Penyelenggaraan sebagian urusan pemerintah dan pelayanan umumdi bidang Perhubungan, Komunikasi dan Informatika.

c. Pembinaan dan pelaksanaan tugas di bidang Perhubungan, Komunikasi dan Informatika, meliputi Pengendalian dan Angkutan, Manajemen Lalulintas, Komunikasi dan Informatika, Terminal dan Perparkiran. 
d. Pelaksanaan urusan kesekretariatan

e. Pelaksanaan tugas lain yang diberikan oleh Walikota sesuai dengan tugas pokok dan fungsinya.

\section{Pembahasan}

\subsection{Sistem yang sedang berjalan}

Pada dasarnya masyarakat di kota Cimahi yang ingin mengetahui jalur rute angkot selama ini masih bertanya kepada orang lain atau bahkan menebak-nebak jurusan angkot dan rute mana yang akan dilalui. Dari hasil penganalisaan penulis, cara ini kurang efektif karena adanya rasa malu untuk bertanya kepada orang lain. Belum lagi jika kita sedang terburu-buru dan tidak tahu ke mana rute angkot yang akan dilalui, maka yang harus dilakukan adalah bertanya kepada orang lain. Selain itu, belum tentu orang yang kita tanya itu tahu dan bisa saja malah memberikan informasi yang salah kepada kita sehingga kita menjadi tersesat kemudian kembali bertanya lagi kepada orang lain sampai mendapatkan jawaban yang benar. Menurut data dari Dinas Perhubungan kota Cimahi, terdapat 3 trayek angkot di kota Cimahi. 3 trayek angkot tersebut adalah:

1. Trayek angkot dalam kota Merupakan trayek angkot yang ada di dalam kota Cimahi.

Tabel 1. Trayek Angkot Dalam Kota Cimahi (Dinas Perhubungan, 2010)

\begin{tabular}{|c|c|c|}
\hline $\begin{array}{l}N \\
0\end{array}$ & Trayek & Rute Yang Dilalui \\
\hline 1 & $\begin{array}{l}\text { Cimindi- } \\
\text { Leuwigajah- } \\
\text { Terminal } \\
\text { Pasar Antri }\end{array}$ & $\begin{array}{l}\text { Pergi : } \\
\text { Cimindi-JI. Mahar Martanegara-Bunderan } \\
\text { Leuwigajah-JI. Baros-JI. Urip. S-JI. Dustira - } \\
\text { JI. Sriwijaya-Terminal Pasar Antri } \\
\text { Pulang: } \\
\text { Cimahi(Terminal Pasar Antri)-JI. Sriwijaya - } \\
\text { JI. Stasion-JI. Gatsu-JI. Baros-Bunderan } \\
\text { Leuwigajah-JI. Mahar Martanegara }\end{array}$ \\
\hline 2 & $\begin{array}{l}\text { Terminal } \\
\text { Pasar Antri Via } \\
\text { Baros- } \\
\text { Cibeber- } \\
\text { Ciseupan }\end{array}$ & $\begin{array}{l}\text { Pergi : } \\
\text { Terminal Pasar Antri-JI. Sriwijaya-J I. } \\
\text { Stasion-JI. Gatsu-JI. Baros-Bunderan Leuwi } \\
\text { Gajah-Cibeber } \\
\text { Pulang: } \\
\text { Cibeber-Bunderan Leuwigajah-JI. Baros- JI. } \\
\text { Urip S-JI. Dustira-JI. Sriwijaya-Terminal } \\
\text { Pasar Antri }\end{array}$ \\
\hline 3 & $\begin{array}{ll}\text { Terminal } & \\
\text { Pasar Antri Via } \\
\text { Contong } \\
\text { Cibeber } \\
\text { Ciseupan }\end{array}$ & $\begin{array}{l}\text { Pergi : } \\
\text { Terminal Pasar Antri-JI. Sriwijaya-JI. } \\
\text { Stasion-JI. Gatsu-JI. Dustira-JI. Contong- JI. } \\
\text { Cibeber } \\
\text { Pulang: } \\
\text { Cibeber-JI.Contong-J I.Sriwijaya-Terminal } \\
\text { Pasar Antri }\end{array}$ \\
\hline
\end{tabular}

2. Trayek angkot lintas kota

Merupakan trayek angkot yang melintasi kota Cimahi.
Tabel 2. Trayek Angkot Lintas Kota Cimahi (Dinas Perhubungan, 2010)

\begin{tabular}{|c|c|c|}
\hline $\begin{array}{l}N \\
0\end{array}$ & Trayek & Rute Yang Dilalui \\
\hline 1 & $\begin{array}{l}\text { a. Leuwipanjang } \\
\text { - Cimahi (Pasar } \\
\text { Antri) } \\
\text { Sangkuriang }\end{array}$ & $\begin{array}{l}\text { Pergi : } \\
\text { Leuwipanjang - JI. H. Amir Machmud - } \\
\text { JI. Gatot Subroto - Jl. Dustira - JI. } \\
\text { Sriwjaya - Terminal Pasar Antri } \\
\text { (Lintasan) - JI. Pasopati - JI. Pojok - JI. } \\
\text { H. Amir Machmud - JI. Sangkuriang - } \\
\text { Terminal Sangkuriang } \\
\text { Pulang : } \\
\text { Terminal Sangkuriang - JI. Encep } \\
\text { Kartawiria - JI. Wiganda Sasmita - JI. } \\
\text { H. Amir Machmud - Leuwipanjang } \\
\text { Pergi : } \\
\text { Leuwipanjang - JI. H. Amir Machmud - } \\
\text { JI. Gatot Subroto - JI. Dustira - JI. } \\
\text { Sriwjaya - Terminal Pasar Antri } \\
\text { (Lintasan) - JI. Pasopati - JI. Pojok - JI. } \\
\text { H. Amir Machmud - Padalarang } \\
\text { Pulang : } \\
\text { Padalarang - JI. Sangkuriang - } \\
\text { Terminal Sangkuriang - JI. Encep } \\
\text { Kartawiria - JI. Wiganda Sasmita - JI. } \\
\text { H. Amir Machmud - Leuwipanjang }\end{array}$ \\
\hline 2 & \begin{tabular}{lr}
\multicolumn{2}{l}{ Leuwipanjang } \\
Cimahi (Pasar \\
Antri) \\
Padalarang \\
Sangkuriang
\end{tabular} & $\begin{array}{l}\text { Pergi : } \\
\text { Leuwipanjang - JI. H. Amir Macmud - } \\
\text { JI. Gatot Subroto - JI. Dustira - JI. } \\
\text { Sriwijaya - Terminal Pasar Antri } \\
\text { (Lintasan) - JI. Pasopati - JI. Pojok - JI. } \\
\text { H. Amir Machmud - Padalarang } \\
\text { Pulang: } \\
\text { Padalarang - JI. Sangkuriang - } \\
\text { Terminal Sangkuriang - JI. Encep } \\
\text { Kartawiria - JI. Wiganda Sasmita - JI. } \\
\text { H. Amir Machmud - Leuwipanjang }\end{array}$ \\
\hline 3 & 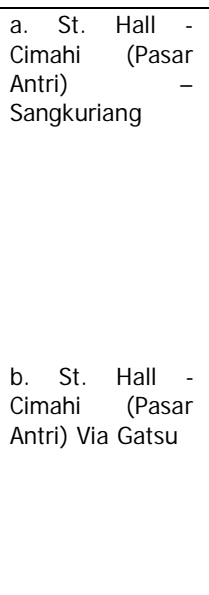 & $\begin{array}{l}\text { Pergi : } \\
\text { St. Hall - JI. H. Amir Machmud - JI. } \\
\text { Gatot Subroto - Jl. Dustira - Jl. } \\
\text { Sriwijaya - Terminal Pasar Antri - } \\
\text { Jl. Pasopati - JI. Pojok - JI. H. Amir } \\
\text { Machmud - Sangkuriang } \\
\text { Pulang : } \\
\text { Sangkuriang - Jl. Encep Kartawiria - JI. } \\
\text { Wiganda Sasmita - JI. Amir Machmud - } \\
\text { St. Hall } \\
\text { Pergi : } \\
\text { St. Hall - JI. H. Amir Machmud - JI. } \\
\text { Gatot Subroto - JI. Dustira - JI. } \\
\text { Sriwijaya - Terminal Pasar Antri } \\
\text { Pulang : } \\
\text { Terminal Pasar Antri - JI. Sriwijaya - JI. } \\
\text { Stasiun - JI. Gatot Subroto - JI. Rd. } \\
\text { Embang.K - JI. Amir Machmud - St. } \\
\text { Hall }\end{array}$ \\
\hline 4 & $\begin{array}{l}\text { St. Hall - Cimahi } \\
\text { (Pasar Antri) - } \\
\text { Padalarang } \\
\text { Sangkuriang }\end{array}$ & $\begin{array}{l}\text { Pergi : } \\
\text { St. Hall - JI. H. Amir Machmud - JI. } \\
\text { Gatot Subroto - Jl. Dustira - JI. } \\
\text { Sriwijaya - Term. Pasar Antri } \\
\text { (Lintasan) - Jl. Pasopati - JI. Pojok - JI. } \\
\text { Amir Machmud - Padalarang } \\
\text { Pulang : } \\
\text { Padalarang - Sangkuriang - JI. Encep } \\
\text { Kartawiria - JI. Wiganda Sasmita - JI. } \\
\text { H. Amir M - St. Hall }\end{array}$ \\
\hline
\end{tabular}


TEDC Vol.10 No.1 Januari 2016: 9-16

Tabel 3. Trayek Angkot Perbatasan Kota Cimahi (Dinas Perhubungan, 2010)

\begin{tabular}{|c|c|c|}
\hline No & Trayek & Rute Yang Dilalui \\
\hline 1 & $\begin{array}{l}\text { Cimahi } \\
\text { (Terminal } \\
\text { Pasar Antri) } \\
\text { - Ciwaruga } \\
\text { (Kabupaten } \\
\text { Bandung) }\end{array}$ & $\begin{array}{l}\text { Pergi : } \\
\text { Terminal Pasar Antri - JI. Sriwijaya - Jl. } \\
\text { Stasion - JI. Gatsu - JI. Rd. Embang A - JI. } \\
\text { H. Amir Machmud - Jl. Daeng MA - } \\
\text { Ciwaruga } \\
\text { Pulang: } \\
\text { Ciwaruga - JI. Daeng MA - JI. H. Amir } \\
\text { Machmud - JI. Gatsu - Jl. Dustira - JI. } \\
\text { Sriwijaya - Terminal Pasar Antri }\end{array}$ \\
\hline 2 & $\begin{array}{l}\text { Cimahi } \\
\text { (Terminal } \\
\text { Pasar Antri) } \\
\text { - } \\
\text { Parongpong } \\
\text { (Kabupaten } \\
\text { Bandung) }\end{array}$ & $\begin{array}{l}\text { Pergi : } \\
\text { Terminal Pasar Antri - JI. Sriwijaya - JI. } \\
\text { Stasion - JI. Gatsu - Jl. Rd. Embang A - JI. } \\
\text { H. Amir Machmud - Jl. Daeng MA - } \\
\text { Parongpong } \\
\text { Pulang: } \\
\text { Parongpong - JI. Daeng MA - JI. H. Amir } \\
\text { Machmud - JI. Gatsu - Jl. Gedung Empat - } \\
\text { Jl. Sriwijaya - Terminal Pasar Antri }\end{array}$ \\
\hline 3 & $\begin{array}{l}\text { Cimahi } \\
\text { (Terminal } \\
\text { Pasar Antri) } \\
\text { - Cimareme } \\
\text { - Batujajar - } \\
\text { Cililin } \\
\text { (Kabupaten } \\
\text { Bandung) }\end{array}$ & $\begin{array}{l}\text { Pergi : } \\
\text { Terminal Pasar Antri (Lintasan) - JI. Pasopati } \\
\text { - JI. Pojok - JI. H. Amir Machmud - } \\
\text { Cimareme - Batujajar - Cililin } \\
\text { Pulang : } \\
\text { Cililin - Batujajar - Cimareme - JI. H. Amir } \\
\text { Machmud - JI. Sangkuriang - JI. Encep K - } \\
\text { JI. Wiganda Sasmita - JI. H. Amir Machmud - } \\
\text { JI. Gatsu - JI. Gedung Empat - Terminal } \\
\text { Pasar Antri }\end{array}$ \\
\hline 4 & $\begin{array}{l}\text { Cimahi } \\
\text { (Terminal } \\
\text { Pasar Antri) } \\
\text { - Patrol - } \\
\text { Soreang } \\
\text { (Kab. } \\
\text { Bandung) }\end{array}$ & $\begin{array}{l}\text { Pergi : } \\
\text { Terminal Pasar Antri - JI. Sriwijaya - JI. } \\
\text { Stasion - Jl. Gatot Subroto - Jl. Baros - } \\
\text { Bunderan - Leuwigajah - Jl. Utama - JI. } \\
\text { Cibodas - JI. Patrol - Soreang } \\
\text { Pulang : } \\
\text { Soreang - Patrol - JI. Cibodas - JI. Utama - } \\
\text { Bunderan - Leuwigajah - JI. Baros - JI. Gatsu } \\
\text { - Jl. Urip S - JI. Dustira - JI. Sriwijaya - } \\
\text { Terminal Pasar Antri }\end{array}$ \\
\hline 5 & $\begin{array}{l}\text { Cimahi } \\
\text { (Terminal } \\
\text { Pasar Antri) } \\
\text { - } \\
\text { Padalarang } \\
\text { (Kab. } \\
\text { Bandung) }\end{array}$ & $\begin{array}{l}\text { Pergi : } \\
\text { Terminal Pasar Antri - JI. Pasopati - JI. Pojok } \\
\text { - Jl. H. Amir Machmud - Padalarang } \\
\text { Pulang : } \\
\text { Padalarang - Jl. H. Amir Machmud - Jl. } \\
\text { Sangkuriang - JI. Encep Kartawiria - JI. } \\
\text { Wiganda Sasmita - Jl. H. Amir Machmud - Jl. } \\
\text { Gatsu - JI. Gd. Empat - JI. Sriwijaya - } \\
\text { Terminal Pasar Antri }\end{array}$ \\
\hline 6 & $\begin{array}{l}\text { Cimahi } \\
\text { (Terminal } \\
\text { Pasar Antri) } \\
\text { - Cimareme } \\
\text { - Batujajar }\end{array}$ & $\begin{array}{l}\text { Pergi : } \\
\text { Terminal Pasar Antri - JI. Pasopati - JI. Pojok } \\
\text { - JI. H. Amir Machmud - Cimareme - } \\
\text { Batujajar } \\
\text { Pulang : } \\
\text { Batujajar - Cimareme - JI. H. Amir Machmud } \\
\text { - JI. Sangkuriang - JI. Encep Kartawiria - JI. } \\
\text { Wiganda Sasmita - JI. H. Amir Machmud - JI. } \\
\text { Gatsu - JI. Gedung Empat - JI. Sriwijaya - } \\
\text { Terminal Pasar Antri }\end{array}$ \\
\hline 7 & $\begin{array}{l}\text { Cimahi } \\
\text { (Term. } \\
\text { Pasar Atas) } \\
\text { - Cipageran } \\
\text { - Puri } \\
\text { Permata - } \\
\text { Cilame } \\
\text { (Kab. } \\
\text { Bandung) }\end{array}$ & $\begin{array}{l}\text { Pergi : } \\
\text { Terminal Pasar Atas - JI. Hj. J ulaeha Karmita } \\
\text { - JI. Kol. Masturi - JI. Cipageran - JI. Puri } \\
\text { Cipageran - Puri Permata Cilame } \\
\text { Pulang : } \\
\text { Cilame - Puri Permata - Puri Cipageran - JI. } \\
\text { Cipageran - JI. Kol. Masturi - JI. Hj. Julaeha } \\
\text { Karmita - Terminal Pasar Atas }\end{array}$ \\
\hline
\end{tabular}

\begin{tabular}{|c|c|c|}
\hline 8 & $\begin{array}{l}\text { Cimahi } \\
\text { (Term. } \\
\text { Pasar Atas) } \\
\text { - Ciawitali - } \\
\text { Ciuyah - } \\
\text { Padaasih - } \\
\text { Pasar } \\
\text { Barokai } \\
\text { (Kabupaten } \\
\text { Bandung) }\end{array}$ & $\begin{array}{l}\text { Pergi : } \\
\text { Terminal Pasar Atas - JI. Hj. Julaeha Karmita } \\
\text { - JI. Encep Kartawiria - JI. Ciawitali - } \\
\text { JI.Ciuyah - JI. Cipanas - JI. Padaasih - Pasar } \\
\text { Barokai } \\
\text { Pulang : } \\
\text { Pasar Barokai - JI. Padaasih - JI. Cipanas - } \\
\text { JI. Ciuyah - JI. Ciawitali - JI. Encep } \\
\text { Kartawiria - JI. Hj. Julaeha Karmita - Cimahi } \\
\text { (Terminal Pasar Atas) }\end{array}$ \\
\hline 9 & $\begin{array}{l}\text { Cimahi } \\
\text { (Terminal } \\
\text { Pasar Atas) } \\
\text { - Cisarua } \\
\text { (Kabupaten } \\
\text { Bandung) }\end{array}$ & $\begin{array}{l}\text { Pergi : } \\
\text { Cimahi (Terminal Pasar Atas) - JI. Hj. } \\
\text { Julaeha Karmita - Jl. Kol. Masturi - Jl. } \\
\text { Paratag - Cisarua } \\
\text { Pulang : } \\
\text { Cisarua - JI. Paratag - JI. Kol. Masturi - JI. } \\
\text { Hj. Julaeha Karmita - Cimahi (Pasar Atas) }\end{array}$ \\
\hline 10 & $\begin{array}{l}\text { Cimahi } \\
\text { (Cimindi) - } \\
\text { Nanjung - } \\
\text { Cipatik } \\
\text { (Kabupaten } \\
\text { Bandung) }\end{array}$ & $\begin{array}{l}\text { Pergi : } \\
\text { Cimahi (Cimindi) - JI. Mahar Martanegara - } \\
\text { Bunderan Leuwigajah - JI. Utama - JI. } \\
\text { Cibodas - JI. Nanjung - Patrol - Cipatik } \\
\text { Pulang : } \\
\text { Cipatik - Patrol - JI. Nanjung - JI. Cibodas - } \\
\text { JI. Utama - Bunderan Leuwigajah - JI. Mahar } \\
\text { Martanegara - Cimahi (Cimindi) }\end{array}$ \\
\hline 11 & $\begin{array}{l}\text { Cimahi } \\
\text { (Cimindi) - } \\
\text { Margaasih } \\
\text { (Kab. } \\
\text { Bandung) } \\
\text { Via Cibaligo }\end{array}$ & $\begin{array}{l}\text { Pergi : } \\
\text { Cimahi (Cimindi) - JI. Mahar Martanegara - } \\
\text { Jl. H. Amir Machmud - JI. Kebon Kopi - JI. } \\
\text { Cijerah - Margaasih } \\
\text { Pulang : } \\
\text { Margaasih - JI. Cijerah - JI. Cibaligo - JI. } \\
\text { Mahar Martanegara - Cimahi (Cimindi) }\end{array}$ \\
\hline 12 & $\begin{array}{l}\text { Cimahi } \\
\text { (Terminal } \\
\text { Pasar Antri) } \\
\text { - } \\
\text { Leuwigajah } \\
\text { - Ciseupan - } \\
\text { Cangkorah - } \\
\text { Batujajar } \\
\text { (Kab. } \\
\text { Bandung) } \\
\end{array}$ & $\begin{array}{l}\text { Pergi : } \\
\text { Cimahi (Terminal Pasar Antri) - Jl. Sriwijaya } \\
\text { - JI. Stasion - Jl. Gatsu - JI. Baros - } \\
\text { Bunderan Leuwigajah - Jl. Kerkof - JI. } \\
\text { Ciseupan - JI. Cangkorah - Batujajar } \\
\text { Pulang : } \\
\text { Batujajar - JI. Cangkorah - JI. Ciseupan - JI. } \\
\text { Kerkof - Bunderan Leuwigajah - JI. Baros - } \\
\text { JI. Urip. S - JI. Dustira - Jl. Sriwijaya - } \\
\text { Terminal Pasar Antri }\end{array}$ \\
\hline 13 & $\begin{array}{l}\text { Cimahi } \\
\text { (Pasar Atas) } \\
\text { - Cidahu - } \\
\text { Tanimulya - } \\
\text { Pakuhaji } \\
\text { (Kab. } \\
\text { Bandung) }\end{array}$ & $\begin{array}{l}\text { Pergi : } \\
\text { Cimahi (Terminal Pasar Atas) - JI. Hj. } \\
\text { Julaeha Karmita - Jl. Kol. Masturi - JI. } \\
\text { Cipageran - Jl. Cidahu - Jl. Tanimulya - } \\
\text { Pakuhaji } \\
\text { Pulang: } \\
\text { Pakuhaji - JI. Tanimulya - JI. Cidahu - JI. } \\
\text { Cipageran - Jl. Kol. Masturi - Jl. Pacinan - } \\
\text { Cimahi (Terminal Pasar Atas) }\end{array}$ \\
\hline 14 & $\begin{array}{l}\text { Cimahi } \\
\text { (Melong } \\
\text { Asih) } \\
\text { Cijerah } \\
\text { (Kota } \\
\text { Bandung) - } \\
\text { Elang (Kota } \\
\text { Bandung) } \\
\end{array}$ & $\begin{array}{l}\text { Pergi : } \\
\text { Cimahi (Melong Asih) - Jl. Cijerah - Jl. Elang } \\
\text { (Kota Bandung) } \\
\text { Pulang : } \\
\text { JI. Elang - Jl. Cijerah - Cimahi (Melong Asih) }\end{array}$ \\
\hline 15 & $\begin{array}{l}\text { Cimahi } \\
\text { (Pesantren) } \\
\text { - Jl. Lembur } \\
\text { Tengah } \\
\text { (Kab. } \\
\text { Bandung) - } \\
\text { Sarijadi } \\
\text { (Kota } \\
\text { Bandung) }\end{array}$ & $\begin{array}{l}\text { Pergi : } \\
\text { Cimahi (Pesantren) - JI. Lembur Tengah - } \\
\text { Poltek ITB - Sarijadi (Kota Bandung) } \\
\text { Pulang : } \\
\text { Sarijadi (Kota Bandung) - Poltek ITB - JI. } \\
\text { Lembur Tengah - Jl. Pesantren (Cimahi) }\end{array}$ \\
\hline
\end{tabular}




\begin{tabular}{|c|l|l|}
\hline 16 & Cimahi & Pergi : \\
& (Terminal & Cimahi (Terminal Sangkuriang) - JI. \\
& Sangkuriang & Sangkuriang - J. H. Amir Machmud - JI. H. \\
& -Tanimulya & Gofur - Cilame (Kabupaten Bandung) \\
& -Cilame & Pulang : \\
& (Kab. & Cilame - JI. H. Gofur - JI. H. Amir Machmud \\
Bandung) & $\begin{array}{l}\text { - JI. Sangkuriang - Terminal Sangkuriang ( } \\
\text { Dapat melintas JI. Kol. Masturi - JI. Hj. } \\
\end{array}$ & Julaeha Karmita) \\
\hline
\end{tabular}

\subsection{Sistem yang akan dibuat}

Dari hasil analisa di atas dapat disimpulkan analisa sistem yang akan dibuat yaitu merancang dan mengimplementasikan aplikasi mobile pencarian jalur angkutan umum di kota Cimahi berbasis android. Aplikasi ini dibangun yang dapat diakses menggunakan smartphone berbasis android. Dalam pembuatannya akan menggunakan program Eclipse Galileo IDE, ADT-Android, SDKAndroid, menggunakan bahasa pemrograman Java, dan juga untuk Database menggunakan PHP MySQL. Dengan adanya aplikasi mobile pencarian jalur angkutan umum di kota Cimahi berbasis android, maka hanya dengan membuka aplikasi tersebut pada sebuah smartphone berbasis android masyarakat dapat memperolah informasi data jurusan angkot dan rute mana saja yang akan dilalui. Cara ini dilakukan dengan cepat tanpa harus bertanya kembali kepada orang lain dan bisa menghemat waktu.

Di dalam aplikasi tersebut, masyarakat bisa mendapatkan informasi tentang daftar jurusan angkot dan juga rute angkot yang dilalui. Lalu juga terdapat gambar angkot-angkot yang ada di kota Cimahi, sehingga untuk memudahkan masyarakat untuk mengenali angkot tersebut.

\subsection{Perancangan Sistem}

Dalam perancangan sistem ini, alat bantu yang digunakan dalam pembuatan sistem yaitu Business Rule dan Use Case Diagram. Perancangan sistem menggunakan use case diagram merupakan bagian dari UML.

\subsubsection{Business Rule}

Business rules merupakan aturan yang berhubungan dengan interaksi dan suatu kejadian dari sistem yang akan dibuat.

Tabel 4 Business Rule

\begin{tabular}{|l|l|}
\hline Kode & Rules \\
\hline R: 1 & $\begin{array}{l}\text { Admin adalah pengontrol dan penanggung jawaban } \\
\text { atas segala kegiatan yang sedang berjalan. }\end{array}$ \\
\hline $\mathrm{R}: 2$ & $\begin{array}{l}\text { Admin adalah pengelola sistem yang memiliki hak } \\
\text { penuh atas aplikasi sistem yang digunakan hingga } \\
\text { databasenya. }\end{array}$ \\
\hline $\mathrm{R}: 3$ & Admin bertugas memelihara dan merawat sistem. \\
\hline
\end{tabular}

\begin{tabular}{|l|l|}
\hline $\mathrm{R}: 4$ & $\begin{array}{l}\text { Login Merupakan tempat untuk masuk ke sistem } \\
\text { yang dilakukan oleh admin }\end{array}$ \\
\hline $\mathrm{R}: 5$ & $\begin{array}{l}\text { Logout untuk keluar dari fungsi dan merupakan hak } \\
\text { yang digunakan oleh admin }\end{array}$ \\
\hline $\mathrm{R}: 6$ & $\begin{array}{l}\text { Tambah Jurusan, Rute, dan foto merupakan untuk } \\
\text { menambahkan semua data yang baru. }\end{array}$ \\
\hline $\mathrm{R}: 7$ & $\begin{array}{l}\text { Edit Jurusan dan Rute, foto merupakan pengeditan } \\
\text { data yang dilakukan oleh admin untuk mengedit } \\
\text { semua data yang akan dan telah di tambah. }\end{array}$ \\
\hline $\mathrm{R}: 8$ & $\begin{array}{l}\text { Hapus berfungsi untuk menghapus semua data } \\
\text { jurusan, data rute serta foto yang terdapat dalam } \\
\text { sistem. }\end{array}$ \\
\hline $\mathrm{R}: 9$ & $\begin{array}{l}\text { Admin memiliki hak penuh atas pemeliharaan dan } \\
\text { perawatan database. }\end{array}$ \\
\hline
\end{tabular}

\subsubsection{Use Case Diagram}

Use Case Diagram digunakan untuk menjalankan dan menjelaskan kegiatan yang dapat dilakukan oleh admin dan pengguna aplikasi. Use case pada aplikasi ini terdiri dari:

1. Menu Daftar Jurusan, dalam menu ini kita bisa melihat daftar jurusan angkot yang ada di kota Cimahi serta rute yang dilaluinya.

2. Menu Gallery, dalam menu ini kita bisa melihat foto-foto angkot yang ada di kota Cimahi.

3. Menu Bantuan, dalam menu menjelaskan menumenu yang ada pada aplikasi mobile pencarian jalur angkutan umum di kota Cimahi berbasis android.

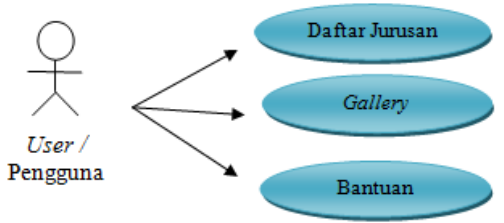

Gambar 1. Use Case Aplikasi mobile

\subsection{Tampilan Aplikasi}

Halaman menu pada aplikasi android adalah halaman yang menampilkan daftar menu-menu pada aplikasi android.

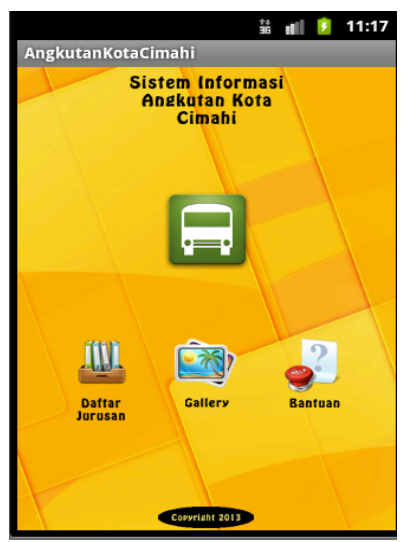

Gambar 2. Tampilan Halaman Menu pada Aplikasi Android 
Menu daftar jurusan pada aplikasi android adalah menu yang menampilkan daftar jurusan angkot kota Cimahi serta rute yang dilaluinya.

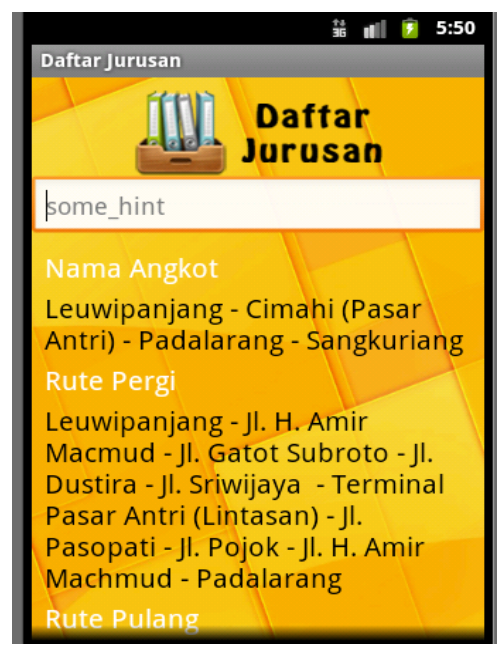

Gambar 3. Tampilan Halaman Menu Daftar J urusan Menu gallery adalah menu yang menampilkan foto-foto angkot yang ada di kota Cimahi.

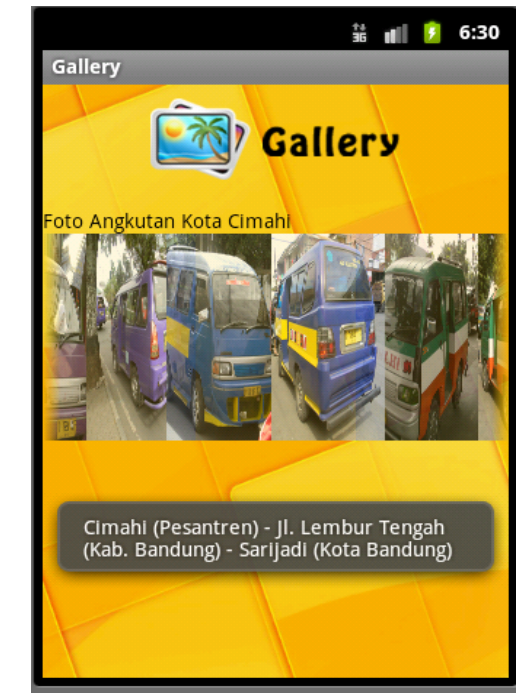

Gambar 4. Tampilan Halaman MenuGallery

\section{Kesimpulan dan Saran \\ 4.1. Kesimpulan}

Dari proses perancangan, pembuatan maupun pengujian aplikasi mobile pencarian jalur angkutan umum di kota Cimahi berbasis androidini dapat disimpulkan sebagai berikut:

1. Perancangan aplikasi mobile pencarian jalur angkutan umum di kota Cimahi berbasis android ini menggunakan use case dan activity diagram sehingga dapat memudahkan dalam implementasi aplikasi.
2. Aplikasi mobile pencarian jalur angkutan umum di kota Cimahi berbasis android ini dapat memudahkan masyarakat untuk mencari jalur angkutan umum di kota Cimahi.

\subsection{Saran}

Aplikasi ini memerlukan pengembangan lebih lanjut. Adapun saran-saran untuk pengembangan sistem ini, antara lain yaitu:

1. Aplikasi diharapkan dapat menambahkan informasi baru seperti tarif angkutan umum kota Cimahi.

2. Mengembangkan aplikasi yang dapat digunakan pada sistem operasi lain seperti Blackberry dan Windows mobile.

\section{Daftar Pustaka}

Dharwiyanti, Sri; Wahono, Romi Satria (2003).Pengantar Unified Modeling Language (UML). Diambil 16 Maret 2013 dari http://www.gobookee.net/

Fatimah, W. N. (2011). Pengenalan tentang sejarah singkat mengenai Eclipse dan cara instalasi Eclipse.PENGENALAN ECLIPSE, Vol. III, No.3, pp. 2-4.

Haryanto, A. (2009). Blog Belajar Pengembangan Aplikasi Android, Blackberry, Jquery, Javascript dan Java. Diambil 19 April 2013, dari http://agusharyanto.net/

http://www.cimahikota.go.id. Alamat website Kota Cimahi.

http://dishub.cimahikota.go.id/profil-1. Alamat website Dinas Perhubungan Kota Cimahi.

Humala, Arief. (2012). Pembuatan Aplikasi Pencarian Halte Transjakarta Terdekat Berbasis Android.

Nugroho, Eddy Prasetyo; Ratnasari, Komala; Ramadhani, Kurniawan Nur; Putro, Budi Laksono.(2009). Rekayasa Perangkat Lunak.

Pratiwi, Rizki; Shiddiqi, Ary Mazharudin; Adi, Baskoro; S, Pratomo.(2012). Aplikasi Mobile Pencarian Rute Transportasi Umum Dengan Algoritma Best-Path Planning Pada Platform Android. Diambil 11 Maret 2013, dari http://www.gobookee.net/

Safaat, N. (2012). pemograman aplikasi mobile smartphone dan tablet pc berbasis android.Bandung: Informatika.

Supardi, Yuniar. (2010). Pemrograman Bahasa Java Bagi Pemula.Bandung: INFORMATIKA. 